$48^{\text {th }}$ AIAA Aerospace Sciences Meeting, January 4-7, 2010, Orlando, Florida

\title{
Receptivity and Transition of Supersonic Boundary Layers Over Swept Wings
}

\author{
P. Balakumar and Rudolph A. King \\ Flow Physics and Control Branch \\ NASA Langley Research Center, Hampton, VA 23681
}

\begin{abstract}
The receptivity, stability, and transition of three-dimensional supersonic boundary layers over (1) a swept cylinder, (2) a swept wing with a sharp leading edge, and (3) a swept wing with a blunt leading edge are numerically investigated for a free-stream Mach number of 3 . These computations are compared to an earlier experimental and computational study performed by Archambaud et al. ${ }^{1}$ The steady flow fields with and without roughness elements are obtained by solving the full Navier-Stokes equations. The $\mathrm{N}$-factors computed in this study at the transition onset locations reported in Ref. 1 for flow over the swept cylinder are approximately 16.5 for traveling crossflow disturbances and 9 for stationary disturbances. The $\mathrm{N}$-factors for the traveling crossflow are high based on our past experiences. However, they are comparatively smaller than those reported by Archambaud et al., who found N-factor values in the range of 20 to 25 for traveling disturbances and 13 to 20 for stationary disturbances. Similarly, the N-factors computed in this study for the traveling and stationary disturbances for the flow over the sharp wing are approximately 7 and 2.5 , respectively, and for the flow over the blunt wing are 6.5 and 4.8 , respectively. Using the envelope method, Archambaud et al. obtained values of approximately 8.0 and 4.0 for the sharp wing case and 16.0 and 12.0 for the blunt wing case.
\end{abstract}

\section{Introduction}

Major technical challenges exist in achieving and maintaining laminar flow over swept wings. These challenges include the accurate prediction of the laminar-to-turbulent transition fronts and the ability to control the different boundary-layer instabilities that cause transition in these flows. These boundarylayer instabilities may include, but are not limited to, attachment-line, crossflow, and TollmienSchlichting instabilities. In this paper, we are concerned with predicting transition in supersonic threedimensional boundary-layer flows over swept wings. Numerous studies have been conducted on the linear stability, nonlinear stability, and prediction of transition in three-dimensional boundary layers. Review articles by $\mathrm{Arnal}^{2}$, Reed \& $\mathrm{Saric}^{3}$, Malik ${ }^{4}$, Bippes ${ }^{5}$ and Saric et al. ${ }^{6}$ give comprehensive overviews of the various instability mechanisms and prediction capabilities. Boundary-layer transition over swept wings near the leading edge is typically caused by the crossflow instability induced by spanwise pressure gradients. Crossflow instability is comprised of both three-dimensional traveling and stationary disturbances.

The transition in swept wing incompressible flows caused by stationary crossflow vortices has been thoroughly investigated both experimentally and numerically ${ }^{5,6}$. The crossflow vortices originate from three-dimensional roughness elements located near the leading edge of the wing where the boundary layer is thin. After the vortices form, the amplitudes of the perturbations grow exponentially downstream due to linear instability and eventually saturate at values of approximately $20 \%$ of the boundary-layer edge values. These saturated vortices persist for long distances and appear as co-rotating vortices aligned very close to the local inviscid streamlines. These vortices lift the low momentum fluid from the wall region towards the outer edge of the boundary layer into regions of high-speed fluid. This produces highly

1 of 23

American Institute of Aeronautics and Astronautics 
inflectional velocity profiles in the streamwise and spanwise directions. These profiles become strongly unstable to high frequency secondary instabilities. After the initiation of the secondary instability, the boundary layer breaks down to turbulence in a relatively short distance. Since the crossflow vortices originate from three-dimensional roughness elements, the transition onset is mainly determined by the roughness amplitude and distribution that exist near the leading edge of the wing. Transition also results from traveling disturbances that are generated by free-stream acoustic and/or turbulent disturbances or by the interaction between free-stream disturbances and surface roughness. The growth rates of the traveling disturbances are generally larger than those for the stationary disturbances. The importance of traveling versus stationary disturbances depends on the environmental conditions such as the surface finish and the unsteady free-stream disturbance levels, as these determine the initial amplitude values of the disturbances. It has been well established in incompressible flows that the stationary crossflow vortices dominate the transition process in most cases except in high turbulence environments. In supersonic compressible flows, the relative importance between traveling and stationary crossflow disturbances is still being investigated.

Several experiments have been performed to measure the transition front in compressible threedimensional boundary layers. Malik and Balakumar ${ }^{7}$ provide a partial list of experiments performed in compressible three-dimensional boundary layers. Most were performed in conventional wind tunnels except those performed in the NASA Langley Supersonic Low Disturbance Tunnel at Mach 3.5 (Creel et al. ${ }^{8}$, Chen et al. ${ }^{9}$, King ${ }^{10}$, and Cattafesta et al. ${ }^{11}$ ). Creel et al. ${ }^{8}$ measured attachment-line transition locations on a swept cylinder. Thermocouples were used to infer transition location on the thin-skin model. Lin and Malik ${ }^{12}$ performed linear stability and transition prediction computations assuming infinite swept cylinder approximations for the Creel et al. experiment and found $\mathrm{N}$-factor values of $\mathrm{N} \sim 11$. Chen et al..$^{9}$ measured the transition onset on a flat plate using a surface pitot tube and on a $5^{\circ}$ half-angle cone at zero angle of attack using thermocouples. The linear stability and transition prediction calculations for the Chen et al. experiment were also performed in that study. The $\mathrm{N}$-factors computed by Chen et al. using the envelop method at the measured transition onset locations were approximately $\mathrm{N} \sim 10$. Similarly, $\mathrm{N}$-factors computed for the flat plate and cone by Balakumar ${ }^{13,14}$ using the constant spanwise wavelength method were $\mathrm{N} \sim 8$ and 9 , respectively. When this experiment was conducted in the noisy conditions consistent with conventional wind tunnels, the transition Reynolds numbers decreased substantially and the $\mathrm{N}$-factors at the transition onset locations were $\mathrm{N} \sim 3$ to 4 . King ${ }^{10}$ measured the transition on a $5^{\circ}$ half-angle sharp cone at several angles of attack using surface pitot tubes. The linear stability and transition prediction calculations for King's experiment were performed by Malik \& Balakumar $^{7}$. The $\mathrm{N}$-factors computed for the most amplified traveling disturbances were about $\mathrm{N} \sim 11$ at the transition front and were about $\mathrm{N} \sim 5$ for the stationary disturbances. Cattafesta et al. ${ }^{11}$ investigated the transition onset on a swept wing using thermocouples on a thin-skin swept wing model. Both temperature sensitive paint and sublimating chemicals were each used to visualize the transition front and stationary crossflow disturbances for one case. The calculated $\mathrm{N}$-factors ${ }^{4,11}$ for the most amplified traveling disturbances using the envelope method were between $\mathrm{N} \sim 10$ to 14 depending on the model surface finish. Cattafesta et al. speculated that the transition was probably dominated by traveling crossflow disturbances, even though the surface flow visualization revealed faint evidence of stationary crossflow disturbances. In the experiments of Refs. 8-11, the disturbances leading to breakdown were not measured and therefore only indirect inference can be made to the actual cause of transition, i.e., whether transition was due to traveling or stationary disturbances.

Archambaud et al. ${ }^{1}$ published the results of a set of transition experiments conducted in the supersonic wind tunnel at ONERA configured with a free-stream Mach number of 3. Their objective was to obtain an experimental database for a range of transition mechanisms. Transition onset locations were acquired on a flat plate, a swept cylinder, a swept wing with a sharp leading edge and a swept wing with a blunt leading edge. The data were obtained at different unit Reynolds numbers and at different sweep angles. Surface pressure distributions were acquired using pressure taps on the swept cylinder and swept wing models. Transition onset locations were determined using thermocouples and infrared images. Linear instability and $\mathrm{N}$-factor computations were performed using local instability and non-local PSE

2 of 23

American Institute of Aeronautics and Astronautics 
(Parabolized Stability Equations) methods. The computed N-factors at the transition onset locations on the flat plate are approximately 4 , consistent with $\mathrm{N}$-factor values obtained by Chen et al. ${ }^{9}$ in a noisy flow environment. The $\mathrm{N}$-factors at transition onset locations for the swept cylinder were found to be very high, ranging from 20 to 25 for traveling crossflow disturbances and 13 to 20 for stationary disturbances. Depending on the unit Reynolds number, the $\mathrm{N}$-factors for the swept wing case with the sharp leading edge ranged from 3 to 11 for the traveling crossflow disturbances and 1 to 10 for the stationary disturbances. Similarly, the $\mathrm{N}$-factors for the swept wing with the blunt leading edge ranged from 11 to 16 for the traveling disturbances and 8 to 12 for the stationary disturbances.

The first objective of the current research is to compute the $\mathrm{N}$-factors for three cases considered by Archambaud et al. ${ }^{1}$ (swept cylinder, swept wing with sharp leading edge, and swept wing with blunt leading edge) and to compare the results of the stability computations. The approach is to compute the mean flow by solving the full Navier-Stokes equations and to perform linear stability theory and PSE computations for each reference configuration and compare the $\mathrm{N}$-factor results to those presented by Archambaud et al. The second objective is to compute the receptivity coefficients for the stationary crossflow vortices that originate from three-dimensional roughness elements. The receptivity coefficients are obtained by performing full Navier-Stokes simulations with three-dimensional roughness elements. The roughness elements are placed parallel and near to the leading edge of the wing and are periodic in the spanwise direction. Computations are performed for the reference configurations and test conditions as those reported in Ref. 1.

The paper is organized in the following manner. The governing equations and a brief discussion about the solution procedure are discussed in section II. Results that include mean flow profiles, linear stability analysis, transition onset predictions, receptivity coefficients and evolution of crossflow vortices originating from the roughness elements are presented in section III. And finally, conclusions are drawn in section IV.

\section{Governing Equations}

The equations solved are the three-dimensional unsteady compressible Navier-Stokes equations in conservation form

$\frac{\partial}{\partial t} Q_{i}+\frac{\partial}{\partial x_{j}}\left(F_{j i}-F_{v j i}\right)=0$,
where $Q_{i}=\left\{\begin{array}{c}\rho \\ \rho E \\ \rho u \\ \rho v \\ \rho w\end{array}\right\}, \quad\left[F_{j i}\right]=\left\{\begin{array}{c}\rho u_{j} \\ (\rho E+p) u_{j} \\ \rho u u_{j}+\delta_{1 j} p \\ \rho v u_{j}+\delta_{2 j} p \\ \rho w u_{j}+\delta_{3 j} p\end{array}\right\}, \quad\left[F_{v i j}\right]=\left\{\begin{array}{c}0 \\ u \tau_{1 j}+v \tau_{2 j}+w \tau_{3 j}-q_{j} \\ \tau_{1 j} \\ \tau_{2 j} \\ \tau_{3 j}\end{array}\right\}$,

$(x, y, z)$ are the Cartesian coordinates, $(u, v, w)$ are the velocity components, $\rho$ is the density, and $p$ is the pressure. $E$ is the total energy per unit mass given by

$$
\begin{aligned}
& E=e+\frac{u^{2}+v^{2}+w^{2}}{2}, \\
& e=c_{v} T, p=\rho R T
\end{aligned}
$$

where $e$ is the internal energy per unit mass and $T$ is the temperature. The shear stress and the heat flux are given by 


$$
\tau_{i j}=\mu\left\{\frac{\partial u_{i}}{\partial x_{j}}+\frac{\partial u_{j}}{\partial x_{i}}-\frac{2}{3} \delta_{i j} \frac{\partial u_{k}}{\partial x_{k}}\right\}, \quad q_{j}=-k \frac{\partial T}{\partial x_{j}} .
$$

The viscosity, $\mu$, is computed using Sutherland's law and the coefficient of conductivity, $k$, is given in terms of a constant Prandtl number, $P r$. The variables $\rho, p, T$ and velocity are non-dimensionalised by their corresponding reference variables $\rho_{\infty}, p_{\infty}, T_{\infty}$, and $\sqrt{R T_{\infty}}$, respectively. The subscript " $\infty$ " denotes free-stream quantities. Additionally, $q_{\infty}$ is defined as the free-stream velocity and $y_{n}$ is the local wallnormal coordinate. For the computation, the equations are transformed from the physical coordinate system $(x, y, z)$ to the computational curvilinear coordinate system $(\xi, \eta, \zeta)$ in a conservative manner.

\section{A. Solution Algorithm}

The governing equations are solved using a $5^{\text {th }}$-order accurate weighted essentially non-oscillatory (WENO) scheme for space discretization and using a $3^{\text {rd }}$-order, total variation diminishing (TVD) RungeKutta scheme for time integration. These methods are suitable in flows with discontinuities or high gradient regions. The governing equations are solved discretely in a uniform structured computational domain where flow properties are known point wise at the grid nodes. In a given direction, the spatial derivatives are approximated to a higher order at the nodes, using the neighboring nodal values in that direction. The resulting equations are then integrated in time to get the point values as a function of time. Since the spatial derivatives are independent of the coordinate directions, multi dimensions can be easily added to the method. It is well known that approximating a discontinuous function by a higher order (two or more) polynomial generally introduces oscillatory behavior near the discontinuity, and this oscillation increases with the order of the approximation. The essentially non-oscillatory (ENO) and the improved WENO methods were developed to maintain the higher-order approximations in the smooth regions and to eliminate or suppress the oscillatory behavior near the discontinuities. These objectives are achieved by systematically adopting or selecting the stencils based on the smoothness of the function that is being approximated. Shu ${ }^{15}$ explains the WENO and the TVD methods and the formulas. Atkins ${ }^{16}$ gives the application of the ENO method to the Navier-Stokes equations. Balakumar et al. ${ }^{17}$ describe in detail the solution method implemented in this computation.

At the outflow boundary, characteristic boundary conditions ${ }^{18}$ are implemented to obtain the flow variables. At the wall, no-slip conditions are used for the velocities and a constant temperature condition is employed for the temperature. The density at the wall is computed from the continuity equation. In the spanwise direction, periodic conditions are imposed at the boundaries. The free-stream values are prescribed at the upper boundary that lies outside the bow shock and simulations are performed using a variable time step until the maximum residual reaches a small value on the order of $10^{-11}$. A CFL number of 0.5 is used in these computations.

The grid stretches in the $\eta$ direction close to the wall and is uniform outside the boundary layer. In the $\xi$ direction, the grid is symmetric about the nose and is very fine near the nose and becomes uniform in the flat region. The grid is uniform in the spanwise $\zeta$ direction. The outer boundary outside of the shock follows a parabola where the vertex is located a short distance upstream of the nose to capture the boundary layer accurately.

\section{Results}

The computations are performed for supersonic flows over (1) a swept cylinder, (2) a swept wing with a sharp leading edge, and (3) a swept wing with a blunt leading edge. Figure 1 shows the schematic diagram of the three geometries. The Cartesian coordinates, $(x, y, z)$, are oriented such that $x$ is along the chord direction perpendicular to the leading edge, $y$ is along the normal direction, and $z$ is along the spanwise direction. $S$ is the distance measured along the surface starting from the leading edge and $\theta$ is 
$48^{\text {th }}$ AIAA Aerospace Sciences Meeting, January 4-7, 2010, Orlando, Florida

the angle measured from the leading edge. Computations are performed for the reference configurations and parameters that were tested in Ref. 1.

\section{Case 1: Swept cylinder}

We consider a supersonic flow over an infinite swept cylinder. The flow parameters and the dimensions for the reference configuration ${ }^{1}$ are given in Table 1 . The transition onset in the experiment occurred at $\theta=31.5^{\circ}$ from the leading edge for this case.

\section{Table 1. Flow parameters for the swept cylinder model}

Cylinder radius: $\mathrm{a}=30 \mathrm{~mm}$

Free-stream Mach number: $M_{\infty}=3.0$

Sweep angle: $\Lambda=50$ degrees

Free-stream Reynolds number: $R e_{\infty}=28.3 \times 10^{6} / \mathrm{m}$.

Free-stream temperature: $T_{\infty}=121.42{ }^{\circ} \mathrm{K}$

Wall temperature: $T_{w}=300.0{ }^{\circ} \mathrm{K}$

Prandtl number: $\operatorname{Pr}=0.70$

Ratio of specific heats: $\gamma=1.4$

Non-dimensional frequency $F=1 \times 10^{-5}$ is equivalent to $29.4 \mathrm{kHz}$

The non-dimensional frequency $F$ is defined as $F=\frac{2 \pi v_{\infty} f}{U_{\infty}^{2}}$,

where $f$ is the frequency in Hertz.

\section{A. Mean flow}

Figure 2 shows the leading-edge bow shock and the density contours obtained from the Navier-Stokes simulation. For this sweep angle of 50 degrees, the Mach number normal to the leading edge is supersonic $\left(M_{\text {normal }}=1.93\right)$. Figures 3(a) and 3(b) depict the computed pressure distribution around the cylinder and the density profiles at three axial stations, $\theta=10.6,15.2$, and $30.0^{\circ}$. To validate the results obtained from the WENO code, mean flow computations were also performed using the well-documented ${\mathrm{CFL} 3 \mathrm{D}^{19}}^{19}$ code. The pressure distribution and the boundary-layer density profiles obtained from the CFL3D computations are also included in Figs. 3(a) and 3(b) for comparison. Figure 3(a) shows the variation of the crossflow Reynolds number around the cylinder. The crossflow Reynolds number is defined based on the maximum crossflow velocity in the direction normal to the inviscid streamline and the distance from the wall to the location where the crossflow velocity is $10 \%$ of its maximum value. The crossflow Reynolds number increases approximately linearly around the cylinder and reaches a value of about 400 near the transition onset point of $\theta=30^{\circ}$. The agreement between the WENO and CFL3D results is excellent. Figures 4(a) and 4(b) show the boundary-layer velocity and the crossflow velocity profiles at different axial stations obtained from the WENO code. Figure 4(a) depicts the velocity profiles along the inviscid streamlines in the wall-normal similarity coordinate and Fig. 4(b) shows the crossflow velocity profiles in the physical coordinate normal to the inviscid streamlines. It is interesting to see that the velocity profiles are almost similar along different axial stations of the cylinder. The boundary-layer thickness increases from a value of $0.17 \mathrm{~mm}$ at $\theta=5^{\circ}$ to a value of $0.19 \mathrm{~mm}$ at $\theta=30^{\circ}$. The maximum crossflow velocity increases with the streamwise direction and reaches a value of $8 \%$ of the free-stream value at $\theta=30^{\circ}$. 


\section{B. Linear instability}

The linear stability and $\mathrm{N}$-factor computations are performed using local and PSE methods for constant spanwise wavelengths. Figures 5(a) and 5(b) show the growth rates and N-factor curves obtained from local stability calculations for the stationary disturbances. To check the consistency of our computations, we also performed the computations using the stability and transition prediction code LASTRAC $^{20}$. The solid lines display the results obtained with LASTRAC and the dashed lines show the results computed using our research code. The results obtained from both codes are identical to three or four decimal places. The growth rates exhibit the distribution characteristics of the crossflow instability. The spanwise wavelengths of the most amplified waves are in the range of 2.0 to $3.0 \mathrm{~mm}$. The neutral point is located approximately $\theta=8^{\circ}$ from the leading edge for the most amplified disturbance with wavelength of $2.5 \mathrm{~mm}$. The results show that the maximum $\mathrm{N}$-factors are about 9.0 for the stationary disturbances at the transition onset location of $\theta=31.5^{\circ}$. Figure 5(b) also includes the results computed using the linear PSE method for a constant spanwise wavelength of $2.5 \mathrm{~mm}$. The $\mathrm{N}$-factors were calculated using growth rates based on $u_{\max }$ and $w_{\max }$. The $\mathrm{N}$-factors based on linear PSE at the transition onset location are approximately 10.0 based on $u_{\max }$ and 9.0 based on $w_{\max }$. These $\mathrm{N}$-factors are significantly smaller than those reported in Ref. 1 of 13 to 22 .

Similarly, Figs. 6(a) and 6(b) display the results for the traveling crossflow disturbances $(f \neq 0)$. The first observation is that the results obtained from the LASTRAC and the research codes are in excellent agreement. The results are given for a frequency range of 24 to $60 \mathrm{kHz}$ and spanwise wavelengths in the range of 2.0 to $3.0 \mathrm{~mm}$. At the smaller frequencies of 24 and $48 \mathrm{kHz}$ and smaller wavelengths of 2 to 2.5 $\mathrm{mm}$, the growth rates are similar to the growth rates for the stationary disturbances. At the higher frequencies of 54 and $60 \mathrm{kHz}$, the growth rates increase steeply from the neutral point to a peak value and drop steeply to lower values. The maximum $\mathrm{N}$-factor obtained near the transition onset location using these parameters is approximately 16.5. This occurs for a disturbance with a frequency of $48 \mathrm{kHz}$ and a spanwise wavelength of $2.5 \mathrm{~mm}$. The $\mathrm{N}$-factor obtained using linear PSE is about 18.0 based on $u_{\max }$. These $\mathrm{N}$-factor values are lower than those reported in Ref. 1 of 20 to 25 . However, these N-factors are still quite high for an experiment performed in a conventional facility and based on our experience in "quiet"-tunnel experiments.

If we extend the computations to higher frequencies and higher wavelengths, we start to get very large unphysical $\mathrm{N}$-factors. We looked at the growth rate curves and observed that the upstream and downstream propagating modes merged near $\theta=14^{\circ}$ for these parameters. This is illustrated in Fig. 7. Figure 7(a) shows the growth rates for three spanwise wavelengths $(2.5,2.55$ and $2.60 \mathrm{~mm})$ at a frequency of $60 \mathrm{kHz}$. For the spanwise wavelength of $2.5 \mathrm{~mm}$, the solid red curve depicts the growth rate for the downstream propagating wave while the dashed red curve shows the growth rate for the upstream propagating wave. The downstream propagating wave results are similar to the results observed in Fig. 6(a). At a spanwise wavelength of $2.55 \mathrm{~mm}$, the growth rate curve exhibits a discontinuity in the slope near $\theta=14^{\circ}$. At a spanwise wavelength of $2.6 \mathrm{~mm}$, the growth rate curve for the downstream propagating wave merges with the growth rate curve for the upstream propagating wave near $\theta=14^{\circ}$ and produces large unphysical growth rates. This phenomenon, known as mode pinching, suggests that beyond a certain parameter space, convective spatially unstable waves cease to exist and the system is susceptible to absolute instability. Interestingly, Lin et al. ${ }^{21}$ discussed this phenomenon when they investigated the stability of a three-dimensional incompressible boundary layer formed on an infinite-swept cylinder. Figure 7(b) shows the corresponding results in the wave number space.

\section{Roughness}

After the parameters for the most amplified disturbances were identified from the linear stability computations, direct numerical simulations were performed (a) to validate the $\mathrm{N}$-factors obtained from the PSE computations and (b) to compute the receptivity coefficients of the stationary crossflow vortices originating from three-dimensional roughness elements. Simulations were performed with a three- 
dimensional, spanwise-periodic roughness strip placed on the surface of the cylinder close to the leadingedge region near the neutral point. The shape of the roughness is in the form

$$
y_{c}(\theta, z)=h e^{-\sigma\left(\frac{\theta-\theta_{r}}{\Delta \theta}\right)^{2}} \cos \beta z \text {. }
$$

Here $y_{c}$ is the height of the roughness normal to the surface of the cylinder, $h$ is the maximum height, $\theta_{r}$ is the surface location of the roughness, $\beta$ is the spanwise wave number, $\Delta \theta$ is related to the spatial extent of the roughness, and $\sigma$ is a constant that determines the width of the roughness around the cylinder. Computations are performed for the most amplified wave with the spanwise wavelength $\lambda_{z}=2 \pi / \beta=2.5$ $\mathrm{mm}$. The parameters $\theta_{r}, h$, and $\sigma$ are given in Table 2. The boundary-layer thickness near $\theta=8.5^{\circ}$ is about $0.18 \mathrm{~mm}$. Simulations were performed for a roughness height, $k(=h)$, of $5.0 \mu \mathrm{m}$. The roughness Reynolds number, $R e_{k, u}=|u|_{\mathrm{k}} h / v_{k}$, for these parameters is about 6.6.

Table 2. Location and height of the roughness on the swept cylinder

\begin{tabular}{|c|c|c|c|c|c|}
\hline$\theta_{\mathrm{r}}(\mathrm{deg})$ & $\mathbf{h}(\mathrm{mm})$ & $\sigma$ & $\Delta \theta(\mathrm{deg})$ & $\mathbf{h} / \delta$ & $\mathbf{R e}_{\mathrm{k}, \mathrm{u}}$ \\
\hline 8.5 & $\mathbf{0 . 0 0 5}$ & $\mathbf{3}$ & $\mathbf{0 . 5}$ & $\mathbf{1} / 36$ & $\mathbf{6 . 6}$ \\
\hline
\end{tabular}

Figure 8 depicts the contours of the spanwise velocity $w$ at approximately half the boundary-layer height at the roughness $(\mathrm{y} \sim 0.05 \mathrm{~mm})$ in the plan view $(\theta, z)$ plane. Figure 8 clearly illustrates the origination of the crossflow vortices from the roughness elements that are located at $\theta=8.5^{\circ}$. The inviscid streamlines immediately downstream of the roughness are almost parallel to the spanwise direction and the crossflow vortices approximately follow these inviscid streamlines. These striations are the footprints of the crossflow vortices observed, for example, in swept-cylinder flow experiments in both low-speed ${ }^{22}$ and high-speed ${ }^{8}$ flows. Downstream of the roughness the crossflow vortices amplify as they approximately follow the inviscid streamlines. Figure 9 shows the $u$-velocity contours in the crosssectional plane $(z, y)$ at different stations along the cylinder and illustrates the characteristics of the crossflow disturbances as they are amplified and eventually form co-rotating vortices. This was observed and described in several experiments ${ }^{6}$ by Saric and colleagues. The crossflow vortices co-rotate and carry the low momentum fluid from the lower part of the boundary layer to the upper part of the boundary layer and accumulate high-speed fluid from the free stream between the vortex and the wall boundary layer. This leads to the formation of strong shear layers in both the normal and spanwise directions. Eventually these shear layers become unstable to high-frequency secondary instabilities ${ }^{23-26}$ and quickly lead to turbulent flow a short distance downstream. Figures 10(a) and 10(b) show the perturbations of the maximum $u$ velocity (normalized by the free-stream velocity $q_{\infty}$ ) generated by the roughness elements using a linear scale and log scale for the perturbations, respectively. We clearly observe the formation of the unstable crossflow vortices from the roughness elements, the exponential growth of the vortices and the eventual nonlinear saturation of the amplitude of the vortices. Figure 10(b) also includes the amplitude of the perturbations computed using linear PSE, which is appropriately scaled to match the simulations. The agreement is very good in the linear region. The computations from the linear theory deviate from the simulation results when the maximum normalized $u$-velocity perturbations reach about 0.035 . This amplitude is equivalent to 0.175 (or $17.5 \%$ ) when it is non-dimensionalised by the boundarylayer edge velocity. The linear growth and early nonlinear saturation are characteristics of stationary crossflow vortices as demonstrated by White et al. ${ }^{26}$ in low-speed experiments. Their measurements, which were conducted in a low disturbance environment, also show that the amplitude at saturation is about $20 \%$ of the boundary-layer edge velocity and is independent of the initial amplitude. From this figure we can calculate the initial amplitude and the receptivity coefficients for the crossflow vortices that

7 of 23

American Institute of Aeronautics and Astronautics 
are generated by the roughness elements using the linear PSE calculations. The initial amplitude of the instability waves near the neutral points is about

$$
\left(\frac{u_{\max }}{q_{\infty}}\right)_{\text {neutral }}=6.45 \times 10^{-5} \quad \text { or } \quad\left(\frac{u_{\max }}{U_{e}}\right)_{\text {neutral }}=0.94 \times 10^{-3} .
$$

In terms of the roughness height, the receptivity coefficient becomes

$$
\frac{\left(\frac{u_{\max }}{U_{e}}\right)_{\text {neutral }}}{\left(\frac{h}{\delta}\right)}=0.035 .
$$

\section{Case 2: Swept wing with a sharp leading edge}

Next we consider a supersonic flow over an infinite swept wing with a sharp leading edge at zero angle of attack as presented in Fig. 1. The airfoil is a biconvex shape with a constant curvature radius. The chord length is $150 \mathrm{~mm}$ and the maximum thickness is $30 \mathrm{~mm}$. A circle with a very small radius of $0.0025 \mathrm{~mm}$ models the leading edge of the wing. The flow parameters and the dimensions are given in Table 3. The transition onset location in the experiment ${ }^{1}$ corresponding to the flow parameters in the table occurred near $x=60 \mathrm{~mm}$ from the leading edge. The computational domain extends in the axial direction from $x=-10$ to $75.0 \mathrm{~mm}$.

\section{Table 3. Flow parameters for the sharp swept wing model}

Chord length: $\mathrm{C}=150 \mathrm{~mm}$

Maximum thickness: $\mathrm{t}=30 \mathrm{~mm}$

Free-stream Mach number: $M_{\infty}=3.0$

Sweep angle: $\Lambda=30$ degrees

Free-stream Reynolds number: $R e_{\infty}=30.0 \times 10^{6} / \mathrm{m}$.

Free-stream temperature: $T_{\infty}=121.42^{\circ} \mathrm{K}$

Wall temperature: $T_{w}=300.0{ }^{\circ} \mathrm{K}$

Non-dimensional frequency $F=1 \times 10^{-5}$ is equivalent to $31.6 \mathrm{kHz}$

The non-dimensional frequency $F$ is defined as $F=\frac{2 \pi v_{\infty} f}{U_{\infty}^{2}}$,

where $f$ is the frequency in Hertz.

\section{A. Mean flow}

Figure 11 shows the density contours obtained from the Navier-Stokes simulation. The normal Mach number is 2.60. Due to the sharp leading edge, the shock is only detached a very small distance of 0.003 $\mathrm{mm}$ from the nose. Figure 12(a) depicts the computed pressure distribution and the crossflow Reynolds number along the wing. The computed pressure distribution agrees with the results obtained from the Newton's law that is given in Ref. 1 . The pressure decreases steeply from the leading edge up to $x / c=$ 
0.001 and then decreases gradually over the main part of the wing. Figure 12(b) displays the crossflow velocity profiles at different axial locations $(x=10,20,40$ and $60 \mathrm{~mm})$. The boundary-layer thickness is very thin near the leading edge and gradually increases from $0.20 \mathrm{~mm}$ at $x=10 \mathrm{~mm}$ to $0.50 \mathrm{~mm}$ at $x=60$ $\mathrm{mm}$. The maximum crossflow velocity also gradually increases from 0.015 at $x=10 \mathrm{~mm}$ to 0.075 at $x=$ $60 \mathrm{~mm}$. The crossflow Reynolds number near the leading edge is very small up to $x=3 \mathrm{~mm}$. It then increases approximately linearly along the wing and reaches a value of 750 near the transition onset location, $x=60 \mathrm{~mm}$.

\section{B. Linear instability}

Figure 13 shows the $\mathrm{N}$-factor results obtained from the local stability and linear PSE calculations for both the traveling and the stationary disturbances. Computations are performed for a constant spanwise wavelength and include curvature effects. The results show that the $\mathrm{N}$-factors at the transition onset point $x=60 \mathrm{~mm}$ are about 7.0 for the traveling disturbances and about 2.5 for the stationary disturbances, as compared to the $\mathrm{N}$-factors computed using the envelop method in Ref. 1 of 8 and 4 for traveling and stationary disturbances, respectively. The frequency and wavelength of the most amplified wave are about $48 \mathrm{kHz}$ and $1.5 \mathrm{~mm}$. The wavelength of the most amplified stationary disturbances is approximately $1.25 \mathrm{~mm}$. The $\mathrm{N}$-factors obtained from linear PSE computations based on $u_{\max }$ are 1.75 and 7.2 for the most amplified stationary and traveling disturbances, respectively.

\section{Roughness}

Similar to the cylinder case, we performed direct numerical simulations with roughness elements placed near the neutral point. A three-dimensional, spanwise-periodic roughness strip is placed on the surface of the wing very close to the leading-edge region near the neutral point. The shape of the roughness is in the form

$$
y_{c}(x, z)=h e^{-\sigma\left(\frac{x-x_{r}}{\Delta x}\right)^{2}} \cos \beta z
$$

Here $y_{c}, h, \beta$, and $\sigma$ are as defined earlier, $x_{r}$ is the surface location of the roughness, and $\Delta x$ is related to the spatial extent of the roughness along the wing. The parameters $x_{r}, \Delta x, h$, and $\sigma$ are given in Table 4 . The boundary-layer thickness near $x=20.0 \mathrm{~mm}$ is about $0.24 \mathrm{~mm}$. Simulations are performed for a spanwise wavelength of $1.5 \mathrm{~mm}$ and for roughness heights, $k$, of $5.0 \mu \mathrm{m}$ and $10 \mu \mathrm{m}$. The roughness Reynolds numbers, $R e_{k, u}=|u|_{k} h / v_{k}$, for these parameters are about 3.4 and 13.2, respectively (where $|u|_{k}$ is the resultant velocity at height $\mathrm{k}$ ).

Table 4. Location and height of the roughness on the sharp swept wing

\begin{tabular}{|c|c|c|c|c|c|}
\hline $\mathbf{x}_{\mathbf{r}}(\mathbf{m m})$ & $\mathbf{h}(\mathbf{m m})$ & $\sigma$ & $\Delta \mathbf{x}(\mathbf{m m})$ & $\mathbf{h} / \mathbf{\delta}$ & $\mathbf{R e}_{\mathbf{k}, \mathbf{u}}$ \\
\hline 20 & $\mathbf{0 . 0 0 5}$ & $\mathbf{3}$ & $\mathbf{0 . 2 5}$ & $\mathbf{1} / 48$ & 3.4 \\
\hline 20 & $\mathbf{0 . 0 1 0}$ & $\mathbf{3}$ & $\mathbf{0 . 2 5}$ & $\mathbf{1} / \mathbf{2 4}$ & $\mathbf{1 3 . 2}$ \\
\hline
\end{tabular}

Figure 14(a) shows the perturbations of the maximum normalized $u$ velocity generated by the roughness elements. We also included the amplitude of the perturbations computed using linear PSE. The agreement is very good in the linear region and the computations from the linear theory deviates when the maximum $u$-velocity perturbations reach about 0.12 . This is equivalent to 0.15 when it is nondimensionalised by the boundary-layer edge velocity. One interesting observation is that the nonlinear saturation occurs near the same amplitude for the small and large roughness elements. The second PSE curve (curve 2, green line) was computed by multiplying the first PSE curve (curve 1, black line) by a factor of 2. That curve exactly goes through the amplitude curve for the large roughness of $0.01 \mathrm{~mm}$.

9 of 23

American Institute of Aeronautics and Astronautics 
This shows the validity of the computations and demonstrates that the generation or receptivity of the crossflow vortices is linear for the roughness heights considered. Another observation is that the initial amplitude of the disturbances slightly downstream of the roughness elements are high, on the order of 0.02 for $h=0.005 \mathrm{~mm}$, compared to the cylinder case (see Fig. 10(b)). From this figure we computed the initial amplitude and the receptivity coefficients for the crossflow vortices that are generated by the roughness. The initial amplitude of the instability waves near the neutral points for the smaller roughness height of $0.005 \mathrm{~mm}$ is approximately

$$
\left(\frac{u_{\max }}{q_{\infty}}\right)_{\text {neutral }}=0.02 \quad \text { or } \quad\left(\frac{u_{\max }}{U_{e}}\right)_{\text {neutral }}=0.029 .
$$

In terms of the roughness height, the receptivity coefficient becomes

$$
\frac{\left(\frac{u_{\max }}{U_{e}}\right)_{\text {neutral }}}{\left(\frac{h}{\delta}\right)}=1.3 .
$$

The receptivity coefficient for this case is about 40 times larger than the coefficient for the cylinder case. This suggests that even though the $\mathrm{N}$-factors for the stationary disturbances are very small, on the order of 2.0, small roughness elements can potentially cause large stationary disturbances that lead to early transition in flows over swept sharp wings.

\section{Blowing/Suction}

To validate the $\mathrm{N}$-factors computed by the linear instability and the PSE methods for the traveling disturbances, simulations with a harmonic point source located on the surface are performed. A blowing/suction distribution in the form

$$
v(x, z, t)_{y=0}=v_{\max } e^{-\sigma\left(\frac{x-x_{r}}{\Delta x}\right)^{2}} \cos \beta z \sin (\omega t)
$$

is prescribed for the vertical $v$-velocity component across a narrow slot parallel to the leading edge on the surface. Computations are performed for a spanwsie wavelength of $1.5 \mathrm{~mm}$ with a frequency of $45 \mathrm{kHz}$. Other parameters are the same as for the roughness elements as given in Table 4. The maximum forcing amplitude is $v_{\max }=0.0001$. Figure 14(b) shows the maximum normalized $u$-velocity fluctuations on a $\log$ scale at a fixed time along the wall and includes the results from the PSE computations. The growth of the disturbances agrees very well between the simulation and PSE results. The linear results start to deviate from the simulated results when the maximum amplitude reaches a value of 0.20 . This again validates the previous PSE results that the $\mathrm{N}$-factor near the transition onset is about 7.2.

\section{Case 3: Swept wing with blunt leading edge}

Next we consider a supersonic flow over an infinite swept wing with a blunt leading edge at zero angle of attack as presented Fig. 1. The airfoil is the same as that in case 2 except for the first $20 \%$ of the airfoil. A parabola with a leading-edge radius of $6 \mathrm{~mm}$ replaced the sharp leading edge. The flow parameters and the dimensions are given in Table 5. The transition onset location in the experiment ${ }^{1}$ for the flow parameters in the table occurred at $x=45 \mathrm{~mm}$ from the leading edge. The computational domain extends from $x=-10$ to $55.0 \mathrm{~mm}$ in the axial direction. 
Table 5. Flow parameters for the blunt swept wing model

Chord length: $\mathrm{C}=150 \mathrm{~mm}$

Maximum thickness: $\mathrm{t}=30 \mathrm{~mm}$

Free-stream Mach number: $M_{\infty}=3.0$

Sweep angle: $\Lambda=30$ degrees

Free-stream Reynolds number: $R e_{\infty}=18.0 \times 10^{6} / \mathrm{m}$.

Free-stream temperature: $T_{\infty}=121.42{ }^{\circ} \mathrm{K}$

Wall temperature: $T_{w}=300.0{ }^{\circ} \mathrm{K}$

Non-dimensional frequency $F=1 \times 10^{-5}$ is equivalent to $19.0 \mathrm{kHz}$

The non-dimensional frequency $F$ is defined as $F=\frac{2 \pi v_{\infty} f}{U_{\infty}^{2}}$,

where $f$ is the frequency in Hertz.

\section{A. Mean flow}

Figure 15 shows the density contours obtained from the Navier-Stokes simulation. The normal Mach number is 2.60 as in case 2. Due to the blunt leading edge, the shock is detached from the nose a distance of $2.8 \mathrm{~mm}$, more than a factor of 900 times the standoff distance for the sharp wing. Figure 16(a) depicts the computed pressure and crossflow Reynolds number distributions along the wing. The computed pressure distribution agrees with the results obtained from the Newton's law that is given in Ref. 1. We also included the results obtained for the sharp wing with the same unit Reynolds number of $18.0 \times 10^{6} / \mathrm{m}$ and the results obtained in the previous case with a unit Reynolds number of $30.0 \times 10^{6} / \mathrm{m}$. Compared to the sharp case, the pressure decreases less aggressively from the leading edge up to $x / c=0.03$ and then decreases gradually similar to the sharp wing case over the main part of the wing. Figure 16(b) displays the crossflow velocity profiles at different axial locations $(x=1,5,10,20$ and $40 \mathrm{~mm})$. The boundarylayer thickness gradually increases from $0.075 \mathrm{~mm}$ at $x=1.0 \mathrm{~mm}$ to $0.50 \mathrm{~mm}$ at $x=40 \mathrm{~mm}$. The maximum crossflow velocity remains almost at a constant value of approximately 0.07 starting from the leading edge. This is very different from case 2 (sharp wing), where the maximum crossflow velocity near the leading edge increases with distance along the wing (see Fig. 12(b)). This is reflected in the crossflow Reynolds number plot in Fig. 16(a). The crossflow Reynolds number increases to about 250 at $5 \%$ of the chord. After 5\% of the chord, the crossflow Reynolds number increases gradually at a near linear rate; however, the rate of increase is smaller than that for the sharp wing case. For the same unit Reynolds number, the crossflow Reynolds number for the sharp wing is smaller than the value for the blunt wing. Hence, the boundary layer over the blunt wing is more unstable to crossflow than the boundary layer over the sharp wing. The crossflow Reynolds number is about 400 near the transition onset location, $x=45 \mathrm{~mm}$.

\section{B. Linear instability}

Figure 17 shows the N-factor results obtained from the local stability and linear PSE calculations for the traveling and the stationary disturbances. Computations are performed for a constant spanwise wavelength and include curvature effects. The results show that the $\mathrm{N}$-factors at the transition onset location, $x=45 \mathrm{~mm}$, are about 6.5 for the traveling disturbances and about 4.8 for the stationary disturbances, as compared to the $\mathrm{N}$-factors using the envelop method reported in Ref. 1 of 12.0 and 16.0 
for the stationary and traveling disturbances, respectively. The frequency and wavelength of the most amplified traveling wave are about $40 \mathrm{kHz}$ and $1.5 \mathrm{~mm}$, respectively. The wavelength of the most amplified stationary disturbances is about $1.00 \mathrm{~mm}$ to $1.25 \mathrm{~mm}$. The $\mathrm{N}$-factors obtained from linear PSE computations based on $u_{\max }$ are 8.0 and 6.2 for the most amplified traveling and stationary disturbances, respectively.

\section{Roughness}

Similar to the sharp wing case, we performed direct numerical simulations with roughness elements placed near the neutral point. The parameters $x_{r}, \Delta x, h$ and $\sigma$ are given in Table 6 . Note that one of the simulations was conducted with the roughness elements placed downstream of the neutral point $\left(x_{r}=3\right.$ $\mathrm{mm}$ ). The boundary-layer thickness near $x=1.0 \mathrm{~mm}$ is about $0.075 \mathrm{~mm}$. Simulations are performed for the most amplified wave with the spanwise wavelength $\lambda_{z}=2 \pi / \beta=1.0 \mathrm{~mm}$ and for roughness heights, $k$, of $1 \mu \mathrm{m}$ and $5 \mu \mathrm{m}$. The roughness Reynolds numbers, $R e_{k, u}=|u|_{\mathrm{k}} h / v_{k}$, for these parameters are about 0.5 and 10.0 , respectively.

Table 6. Location and the height of the roughness on the blunt swept wing

\begin{tabular}{|c|c|c|c|c|c|}
\hline $\mathbf{x}_{\mathbf{r}}(\mathbf{m m})$ & $\mathbf{h}(\mathbf{m m})$ & $\sigma$ & $\Delta \mathbf{x}(\mathbf{m m})$ & $\mathbf{h} / \boldsymbol{\delta}$ & $\mathbf{R e}_{\mathrm{k}, \mathrm{u}}$ \\
\hline 1 & $\mathbf{0 . 0 0 5}$ & 3 & $\mathbf{0 . 2 5}$ & $1 / 15$ & $\mathbf{1 2 . 2}$ \\
\hline 1 & $\mathbf{0 . 0 0 1}$ & 3 & $\mathbf{0 . 2 5}$ & $1 / 75$ & $\mathbf{0 . 6}$ \\
\hline 3 & $\mathbf{0 . 0 0 1}$ & 3 & $\mathbf{0 . 2 5}$ & $1 / 110$ & $\mathbf{0 . 5}$ \\
\hline
\end{tabular}

Figure 18 depicts the contours of the $u$ velocity at half the boundary layer height $(\mathrm{y} \sim 0.05 \mathrm{~mm})$ in the plan view $(\theta, z)$ plane for the case $x_{r}=1.0 \mathrm{~mm}$ and $h=0.001 \mathrm{~mm}$. These are the footprints of the stationary crossflow vortices that originate from the roughness elements. The sweep angle in this case, 30 degrees, is smaller than that for the cylinder case, 50 degrees. Hence the crossflow vortices near the leading edge are not as curved as they are for the cylinder case. Figure 19 displays the $u$-velocity contours in the cross-sectional planes $(z, y)$ at different stations along the wing. The observations are similar to those discussed previously. The crossflow vortices amplify downstream and develop strong shear layers in both the normal and the spanwise directions.

Figure 20(a) shows the perturbations of the maximum $u$ velocity generated by the roughness elements. We also included the amplitude of the perturbations computed using linear PSE. The agreement is very good in the linear region and the computations from the linear theory deviate when the maximum $u$ velocity perturbations reach about 0.18 . Again, this is equivalent to 0.28 when it is non-dimensionalised by the boundary-layer edge velocity. As we observed earlier, the nonlinear saturation occurs near the same amplitude for the small and large roughness elements. The second PSE curve (curve 5, pink line) was computed by multiplying the first PSE curve (curve 1, black line) by a factor of 5 . That curve does not exactly go through the amplitude curve for the large roughness of $0.005 \mathrm{~mm}$. Thus, the receptivity or generation of the crossflow vortices is nonlinear for this large roughness height. As before, we calculate the initial amplitude and the receptivity coefficients for the crossflow vortices that are generated by the roughness. The initial amplitude of the instability waves near the neutral points for the smaller roughness height of $0.001 \mathrm{~mm}$ located at $x_{r}=1.0 \mathrm{~mm}$ is about

$$
\left(\frac{u_{\max }}{q_{\infty}}\right)_{\text {neutral }}=0.003 \quad \text { or } \quad\left(\frac{u_{\max }}{U_{e}}\right)_{\text {neutral }}=0.009 .
$$

In terms of the roughness height, the receptivity coefficient becomes 


$$
\frac{\left(\frac{u_{\max }}{U_{e}}\right)_{\text {neutral }}}{\left(\frac{h}{\delta}\right)}=0.66 .
$$

The receptivity coefficient for this case is still large compared to the cylinder case by about 20 times; however, it is about 0.5 times smaller than the value for the sharp wing case. We also performed similar simulations with the roughness elements placed at $x_{r}=3.0 \mathrm{~mm}$ and $h=0.001 \mathrm{~mm}$. We note that the neutral point is approximately located near $\mathrm{x}=1.5 \mathrm{~mm}$. Since the boundary layer is thicker at $x=3.0 \mathrm{~mm}$ compared to $x=1.0 \mathrm{~mm}$, the parameter $h / \delta$ decreases to $1 / 110$ in this case. Figure 20(a) shows that the initial amplitude and hence the receptivity coefficient is about 3.5 times smaller than the value obtained when the roughness is located just upstream of the neutral point.

\section{Blowing/Suction}

Similar to the sharp wing case, unsteady blowing and suction simulations are performed for the blunt wing case for a spanwsie wavelength of $1.5 \mathrm{~mm}$ with a frequency of $30 \mathrm{kHz}$. Other parameters are the same as those given in Table 6. The maximum forcing amplitude is $v_{\max }=0.0001$. Figure $20(\mathrm{~b})$ shows the maximum $u$-velocity fluctuations on a $\log$ scale at a fixed time along the wall and includes the results from the PSE computations using the same mean flow solution. The growth of the disturbances agrees very well between the simulation and PSE results. Again the linear results start to deviate from the simulated results when the maximum amplitude reaches a value of 0.20 . This again validates the previous PSE results that the $\mathrm{N}$-factor near the transition onset is about 8.0.

\section{Summary and Conclusions}

The receptivity, stability and transition of three-dimensional supersonic boundary layers over (1) a swept cylinder (2) a swept wing with a sharp leading edge and (3) a swept wing with a blunt leading edge are numerically investigated for a free-stream Mach number of 3. The $\mathrm{N}$-factors, obtained based on transition onset locations reported by Archambaud et al. ${ }^{1}$, are summarized in the Table 7. The N-factors are computed using the linear stability method with constant spanwise wavelength. The $\mathrm{N}$-factors for the flow over the swept cylinder are about 16.5 for the traveling crossflow disturbances and 9 for the stationary disturbances. The $\mathrm{N}$-factors at the transition onset for the traveling disturbances are seemingly high based on our past experience. In the computations of Archambaud et al., they obtained values in the range of 20 to 25 for traveling disturbances and 13 to 20 for stationary disturbances. Our results also showed that beyond a certain parameter range in frequency and spanwise wavelength, convective spatially growing waves cease to exist. The boundary layers may be susceptible to an absolute instability. The $\mathrm{N}$-factors for the traveling and stationary disturbances are about 7.0 and 2.5 for the flow over the sharp wing case and 6.5 and 4.8 for the flow over the blunt swept wing case, respectively. Using the envelope method, Archambaud et al. obtained values in the range 8.0 and 4.0 for the sharp wing case and 16.0 and 12.0 for the blunt wing case.

Receptivity computations for the flow over the swept cylinder show that the roughness elements are less efficient in generating the stationary crossflow vortices. The receptivity coefficients based on the maximum $u$-velocity and surface roughness heights for the stationary crossflow vortices originating from small three-dimensional roughness elements located near the neutral points are 0.035, 1.30 and 0.66 for the cylinder, the sharp wing and the blunt wing, respectively. Compared to the cylinder case, the receptivity coefficients are much larger for both wings (factors of 37 and 19 for the sharp and blunt wings, respectively). Based on the transition location measurements acquired by Archambaud et al., there is no direct evidence as to the cause of transition, i.e., stationary or traveling disturbances. They cited no roughness measurements for the cylinder but values of $0.2 \mu \mathrm{m}$ rms and $2 \mu \mathrm{m}$ maximum were cited for the swept wings with metallic surfaces. If we were to assume that the transition was predominantly caused by stationary disturbances for the three cases and that the surface roughness for both the metallic cylinder

13 of 23 
and swept wing surfaces were similar, then these suggest that the expected $\mathrm{N}$-factors for the stationary disturbances (based only on their receptivity to roughness and an assumed amplitude-based transition criterion) at the transition onset locations will be smaller for the swept wing flows as compared to the cylinder flow. And based on relative magnitudes, the flow over the sharp swept wing is expected to have the smallest $\mathrm{N}$-factor of the three configurations. These are the trends observed from the $\mathrm{N}$-factor calculations in Table 7.

\section{Table 7. N-factors at the transition onset locations and the receptivity coefficients}

\begin{tabular}{|c|c|c|c|}
\hline & Stationary & Traveling & $\begin{array}{c}\text { Receptivity } \\
\text { coefficient }\end{array}$ \\
\hline Cylinder & 9.0 & 16.5 & 0.035 \\
\hline Sharp wing & 2.5 & 7.0 & 1.30 \\
\hline Blunt wing & 4.8 & 6.5 & 0.66 \\
\hline
\end{tabular}

\section{Acknowledgments}

We are grateful to Dr. Chau-Lyan Chang from the Computational Aero-Sciences Branch, NASA Langley Research Center for providing the LASTRAC computations presented in this paper.

\section{References}

1. Archambaud, J. P., Louis, F., Séraudie, A., Arnal, D. and Carrier, G., "Natural Transition in Supersonic Flows: Flat Plate, Swept Cylinder, Swept Wing," AIAA Paper 2004-2245, 2004.

2. Arnal, D. "Boundary Layer Transition: Predictions Based on Linear Theory," Progress in transition modeling, AGARD Rep. No. 793, 1994.

3. Reed, H. L., and Saric, W. S., "Linear Stability Theory Applied to Boundary Layers," Annual Review of Fluid Mechanics, Vol. 28, pp. 389-428, 1996.

4. Malik, M. R., "Boundary-Layer Transition Prediction Toolkit,” AIAA Paper 1997-1904, 1997.

5. Bippes, H., "Basic experiments on transition in three-dimensional boundary layers dominated by crossflow instability," Progress in Aerospace Sciences, Vol. 35, pp. 363-412, 1999.

6. Saric, W. S., Reed, H. L., and White, E. B., "Stability and Transition of Three-Dimensional Boundary Layers," Annual Review of Fluid Mechanics, Vol. 35, pp. 413-440, 2003.

7. Malik, M. R., and Balakumar, P., "Instability and Transition in Three-Dimensional Supersonic Boundary Layers," AIAA Paper 1992-5049, 1992.

8. Creel, T. R., Beckwith, I. E., and Chen, F. J., "Transition on Swept Leading Edges at Mach 3.5," Journal of Aircraft, Vol. 24, No. 10, pp. 710-717, 1987.

9. Chen, F. J., Malik, M. R., and Beckwith, I. E., "Comparison of Boundary Layer transition on a Cone and Flat Plate at Mach 3.5,” AIAA Paper 1988-0411, 1988.

14 of 23

American Institute of Aeronautics and Astronautics 
$48^{\text {th }}$ AIAA Aerospace Sciences Meeting, January 4-7, 2010, Orlando, Florida

10. King, R., A., "Three-dimensional boundary layer transition on a cone at Mach 3.5", Experiments in Fluids, Vol. 13, pp. 305-314, 1992.

11. Cattafesta, L. N., and Iyer, V., Masad, J. A., King, R. A., and Dagenhart, J. R., "Three-Dimensional boundary layer transition on a swept wing at Mach 3.5," AIAA Journal, Vol. 33, No. 11, pp. 2032-2037, 1995.

12. Lin, R.-S. and Malik, M. R., "Stability and Transition in Compressible Attachment-Line boundary-Layer Flow," SAE Paper 952041, 1995.

13. Balakumar, P., "Receptivity of a Supersonic Boundary Layer To Acoustic Disturbances," AIAA Journal, Vol. 47, No. 5, pp. 1069-1078, 2009.

14. Balakumar, P., "Receptivity of Supersonic Boundary Layers Due to Acoustic Disturbances Over Blunt Cones," AIAA Paper 2007-4491, 2007.

15. Shu, Chi-Wang, "Essentially Non-Oscillatory and Weighted Essentially Non-Oscillatory Schemes for Hyperbolic Conservation Laws," NASA/CR-97-206253 and ICASE Report No. 97-6, 1997.

16. Atkins, H. L., "High-Order ENO Methods for the Unsteady Compressible Navier-Stokes Equations," AIAA Paper 1991-1557, 1991.

17. Balakumar, P., Zhao, H., and Atkins, H., "Stability of Hypersonic Boundary Layers Over a Compression Corner," AIAA Paper 2002-2848, 2002.

18. Sesterhenn, J., "A Characteristic-type Formulation of the Navier-Stokes Equations for High Order Upwind Schemes," Computers \& Fluids, Vol. 30, pp. 37-67, 2001.

19. Krist, S. L., Biedron, R. T., and Rumsey, C. L., "CFL3D User's Manual (Version 5.0),” NASA TM-1998208444, 1998.

20. Chang, C. L., "Linear Stability and Transition Analysis Code (LASTRAC) Version 1.2 User Manual," NASA/TM-2004-213233, 2004.

21. Lin, R.-S., Li, F., and Malik, M. R., "Response of Swept Leading-Edge Flows to Line Impulsive Excitation," AIAA Paper 1999-0815, 1999.

22. Poll, D. I. A., "Some observations of the transition process on the windward face of a long yawed cylinder," Journal of Fluid Mechanics, Vol. 150, pp. 329-356, 1985.

23. Reibert, M. S., Saric, W. S., Carrillo, Jr. R. B., and Chapman, K. L, "Experiments in Nonlinear Saturation of Stationary Crossflow Vortices in a Swept-Wing Boundary Layer," AIAA Paper 1996-0184, 1996.

24. Kohama, Y., Saric, W. S., and Hoos, J. A., "A high-frequency, secondary instability of crossflow vortices that leads to transition," In Proceedings of the Royal Aeronautical Society Conference on: Boundary-Layer Transition and Control. 1991.

25. Malik, M., Li, F., and Chang, C., "Crossflow disturbances in three-dimensional boundary layers; Nonlinear development, wave interaction and secondary instability," Journal of Fluid Mechanics, Vol. 268, pp. 1-36, June 1994.

26. White, E. B., and Saric, W. S., "Application of Variable Leading-Edge Roughness for Transition Control on Swept Wings," AIAA Paper 2000-0283, 2000. 
(1) Swept circular cylinder

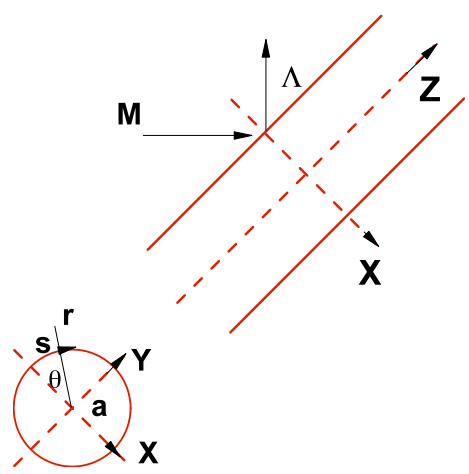

(2) Swept wing sharp leading edge

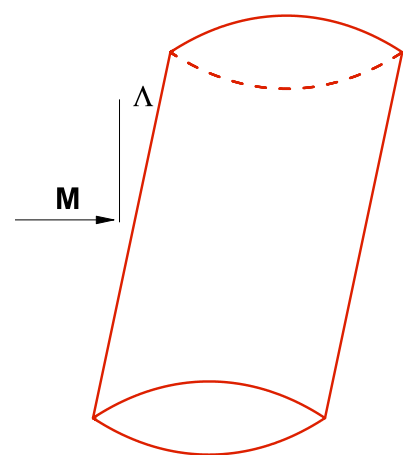

(3) Swept wing blunt leading edge

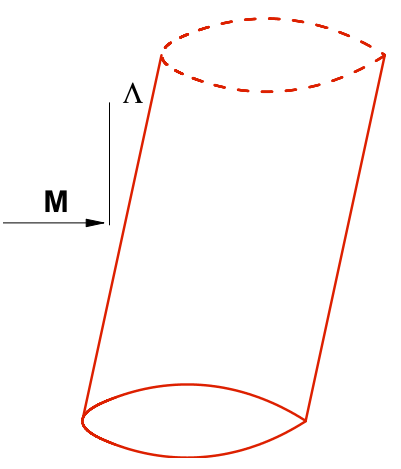

Figure 1. Supersonic flows over an infinite swept cylinder, a biconvex sharp wing, and a biconvex blunt wing.

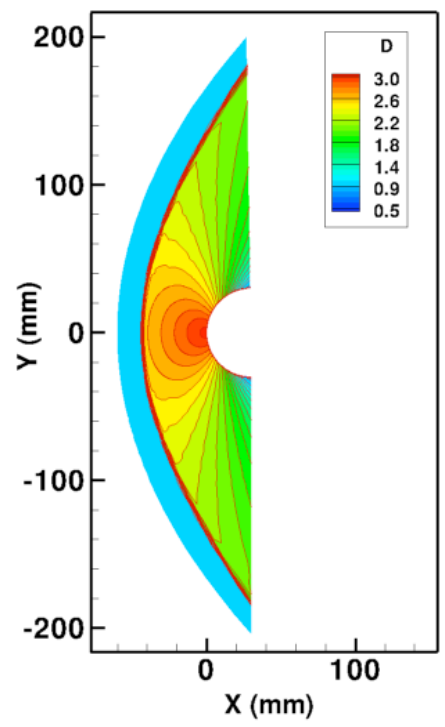

Figure 2. Contours of density for flow over an infinite swept cylinder at $M=3.0$.

(a)

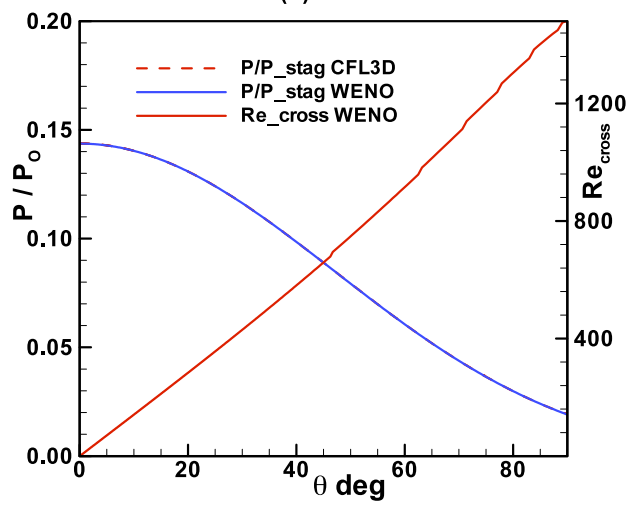

(b)

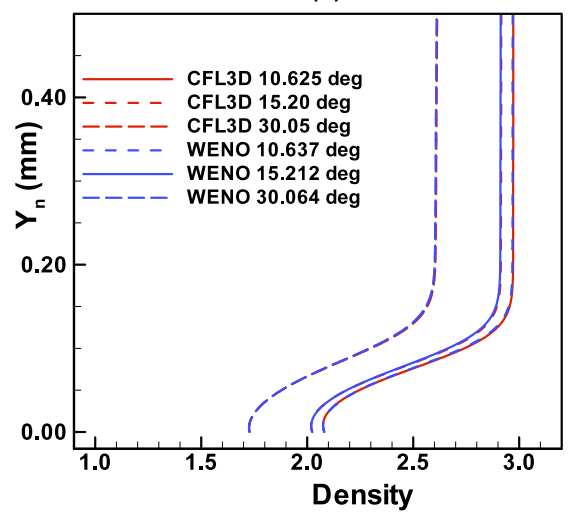

Figure 3. Computed (a) pressure distributions from the WENO and the CFL3D codes and the crossflow Reynolds number around the cylinder and (b) the density profiles obtained with the WENO and CFL3D codes. 
(a)

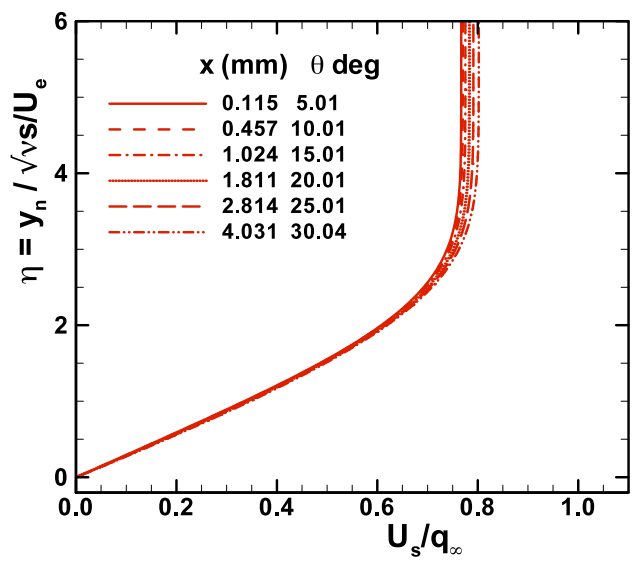

(b)

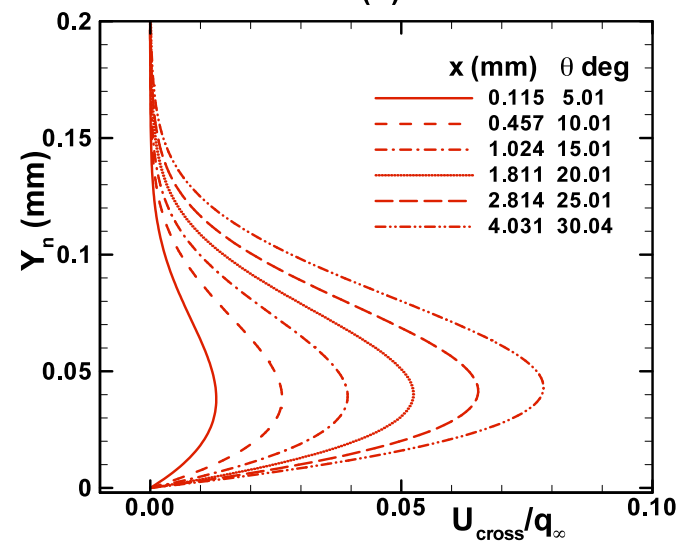

Figure 4. Boundary-layer (a) velocity and (b) crossflow velocity profiles at different axial locations for the flow over a swept cylinder.

(a)

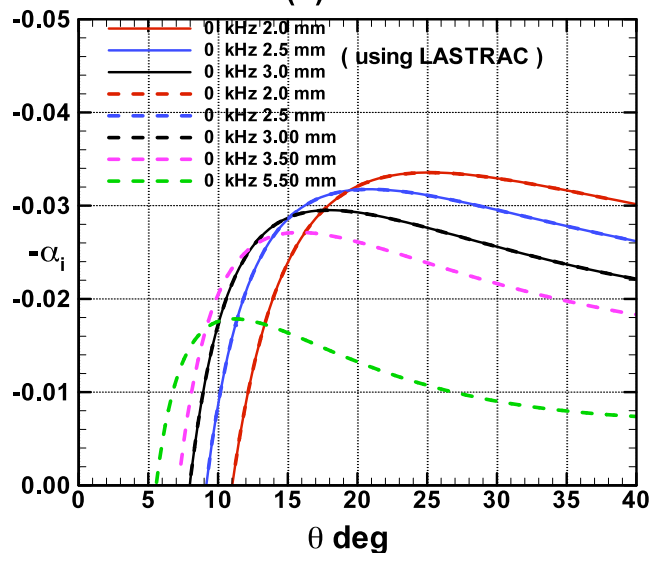

(b)

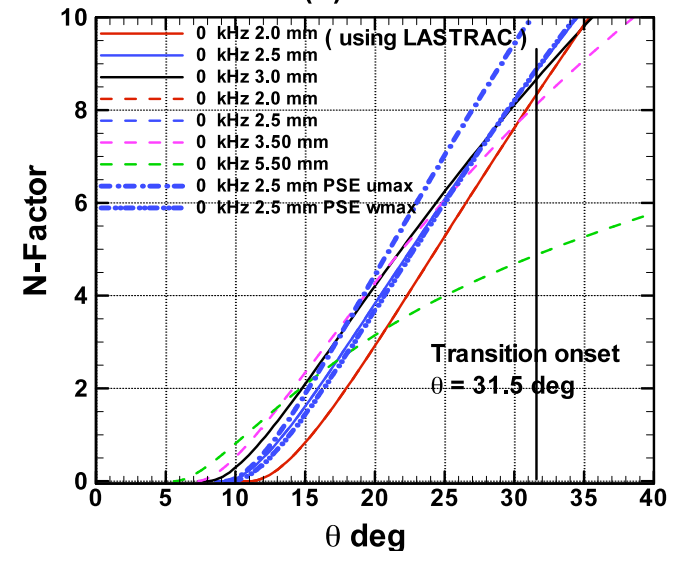

Figure 5. (a) Growth rates and (b) $\mathrm{N}$-factor curves obtained from local stability computations for the stationary disturbances along the cylinder.

(a)

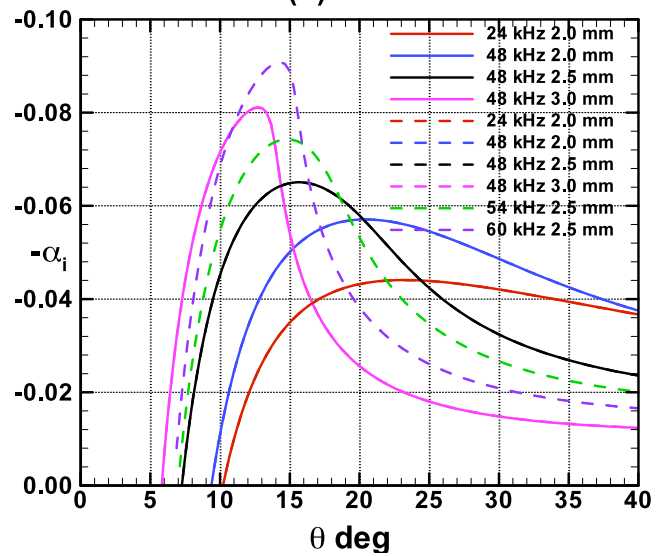

(b)

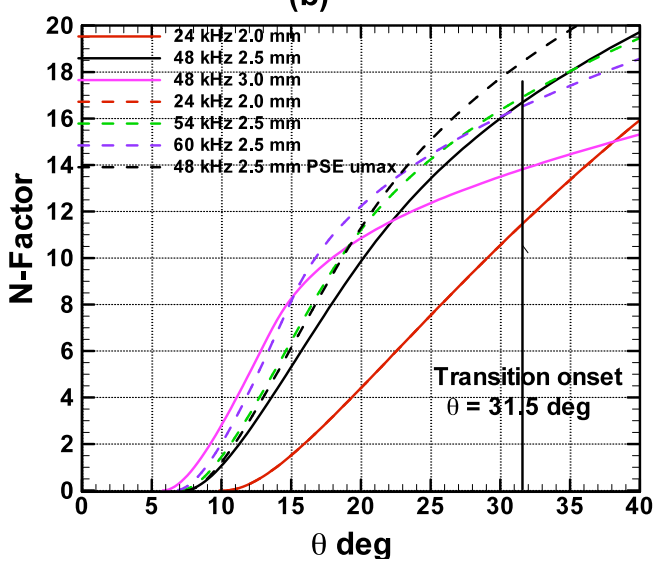

Figure 6. (a) Growth rates and (b) N-factor curves obtained from local stability computations for the traveling disturbances along the cylinder.

17 of 23

American Institute of Aeronautics and Astronautics 
(a)

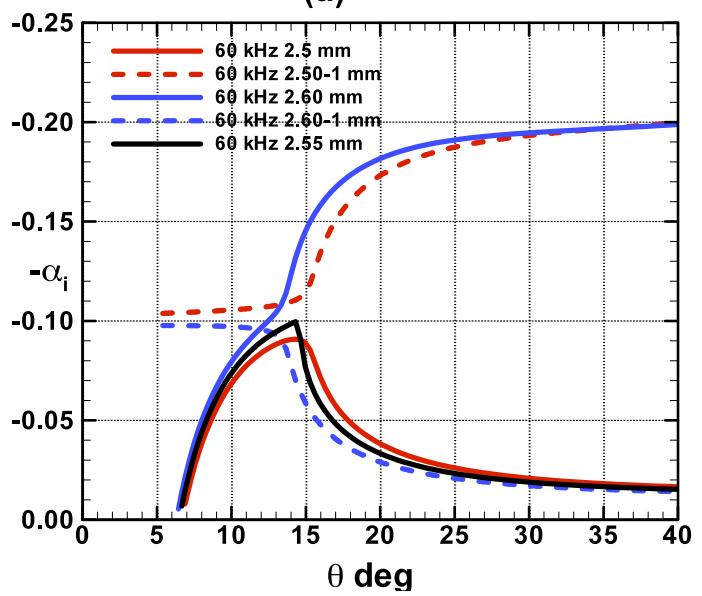

(b)

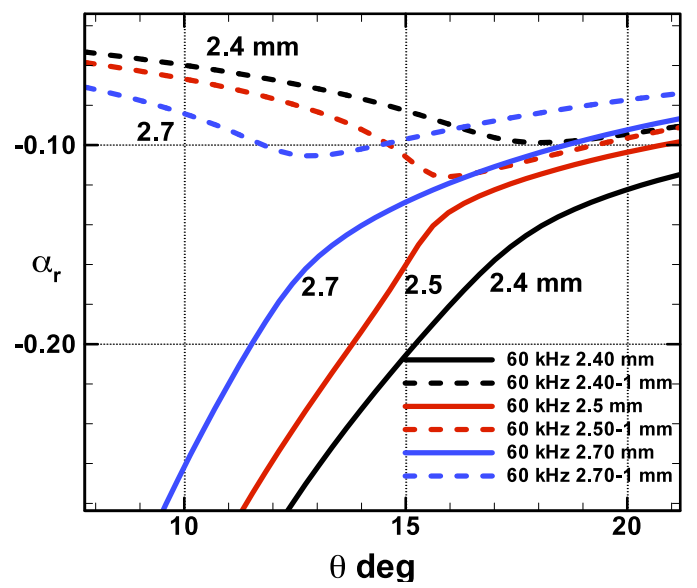

Figure 7. (a) Growth rates and (b) wavenumbers obtained from local stability computations for the traveling disturbances along the cylinder.

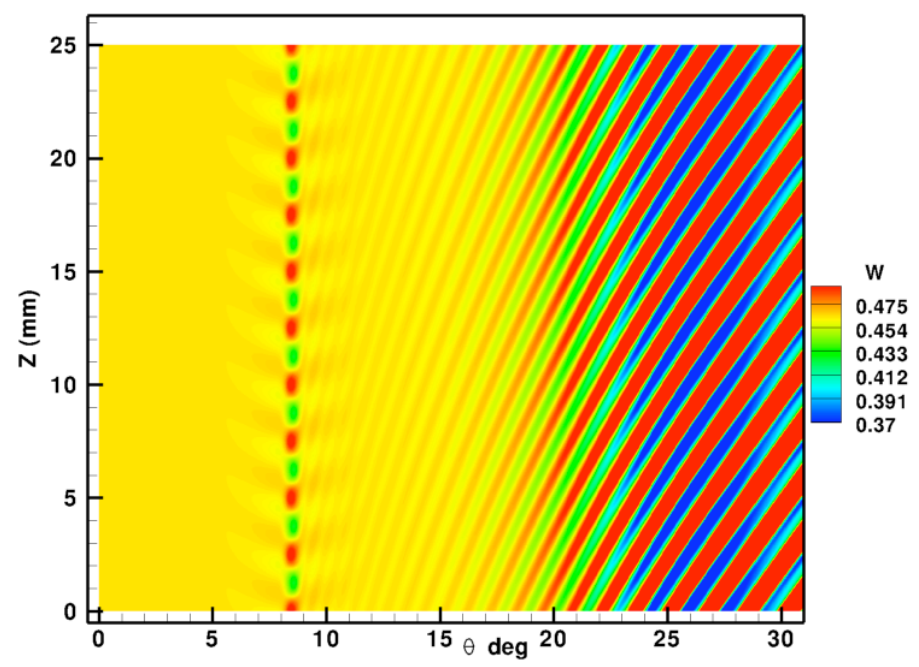

Figure 8. Contours of the $w$ velocity in the plan view $(\theta, z)$ plane for the cylinder. 

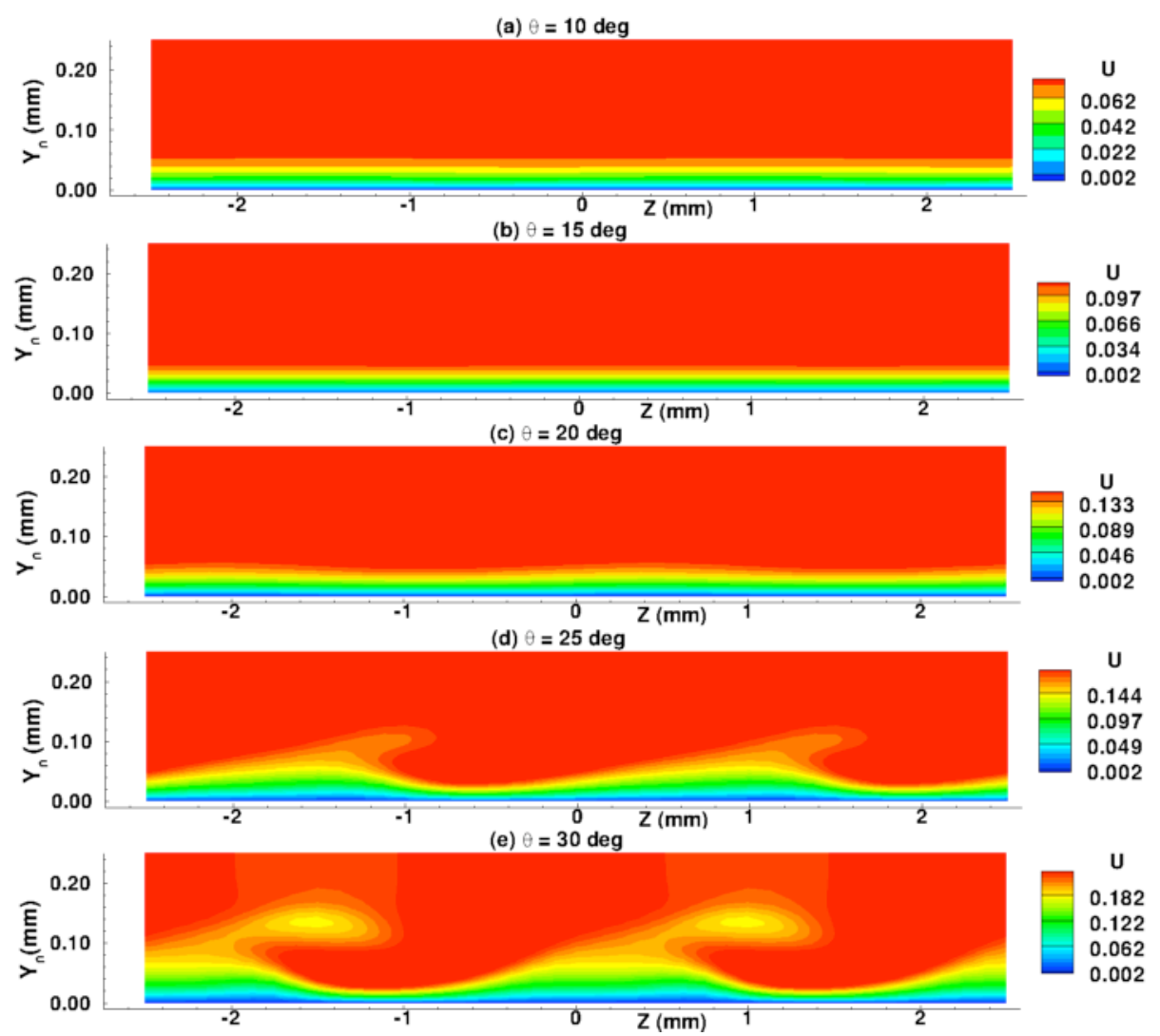

Figure 9. Contours of the $u$ velocity in the cross-sectional planes $(y, z)$ at different stations along the cylinder.
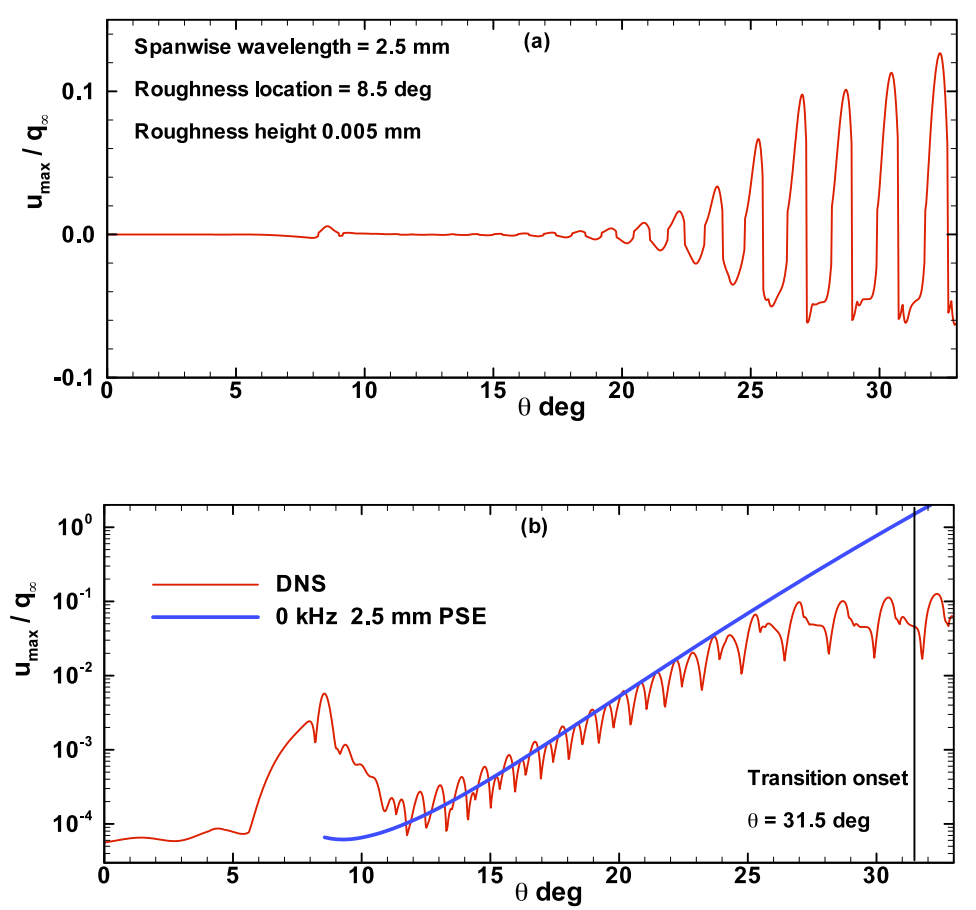

Figure 10. Perturbations of the maximum $u$-velocity component along the cylinder (a) in linear scale and (b) in log scale for comparison with the PSE. 


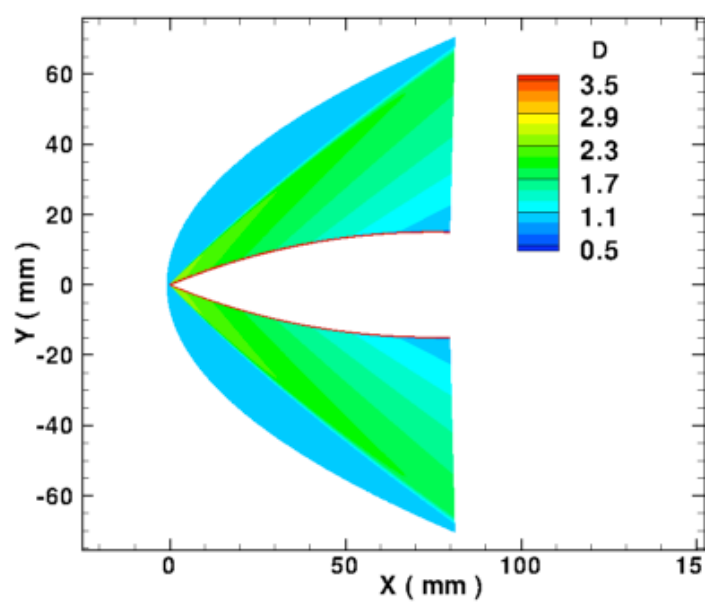

Figure 11. Contours of density for flow over an infinite swept wing with a sharp leading edge at $M=3.0$.
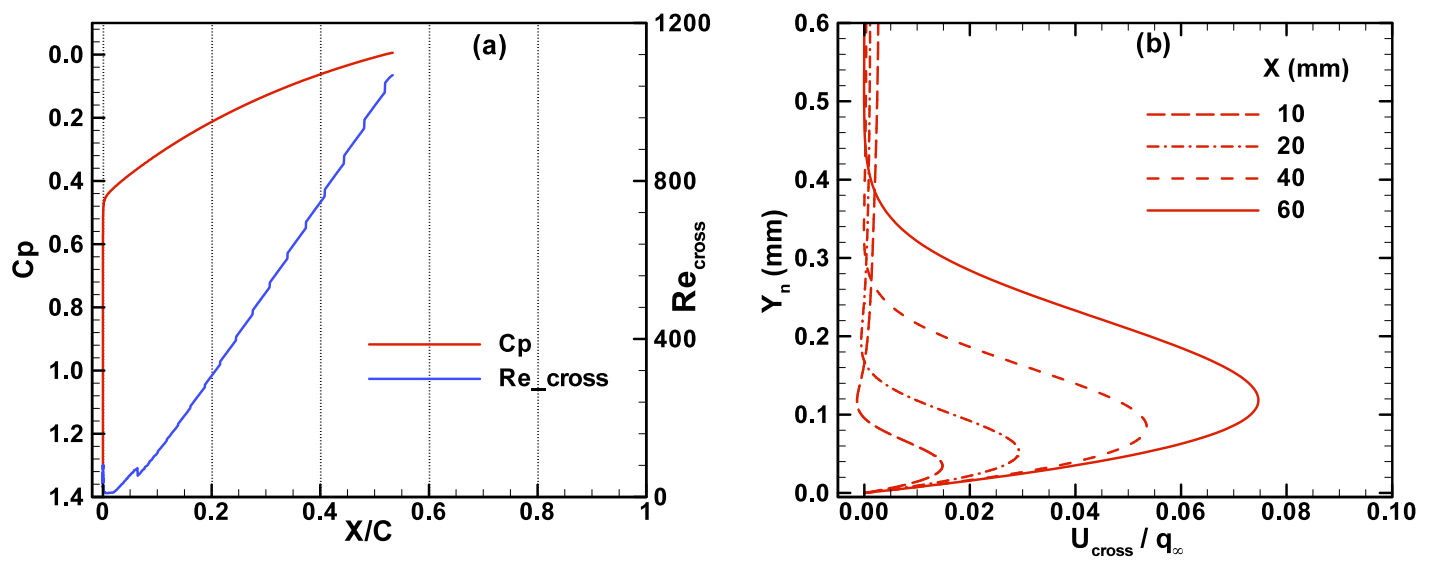

Figure 12. Computed (a) pressure distribution and the crossflow Reynolds number and (b) crossflow velocity profiles along the sharp wing.

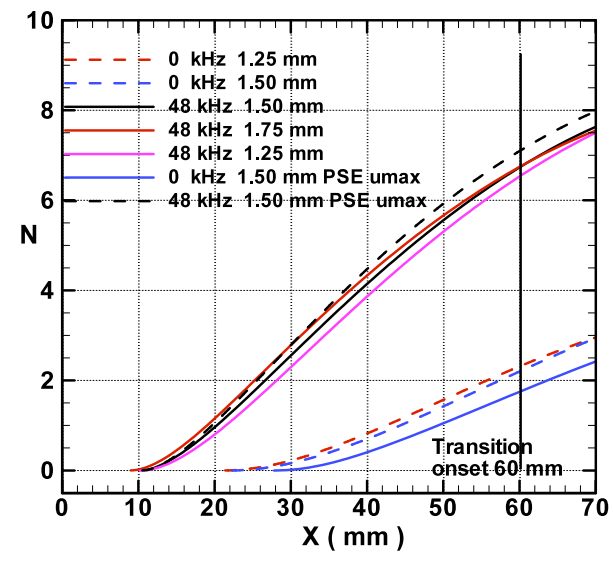

Figure 13. N-factor curves obtained from local stability computations for the traveling and stationary disturbances for the sharp wing. 
(a)

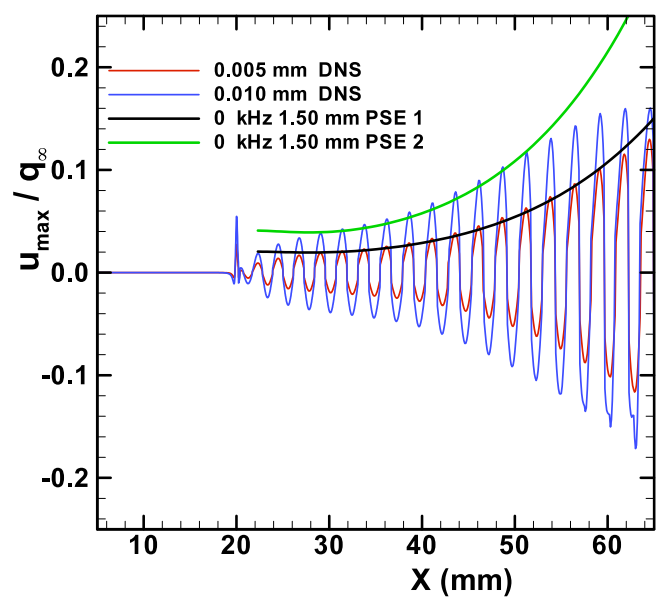

(b)

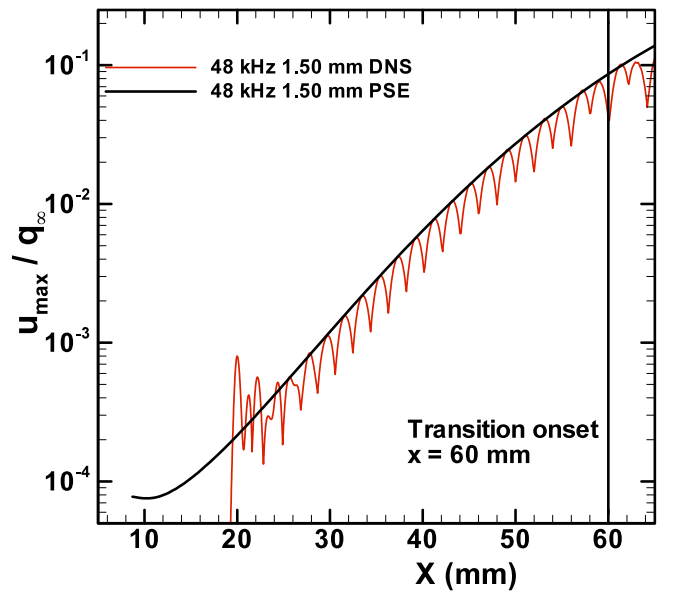

Figure 14. Perturbations of the maximum $u$-velocity component and PSE results along the sharp wing for perturbations (a) generated by the roughness and (b) generated by the blowing and suction.

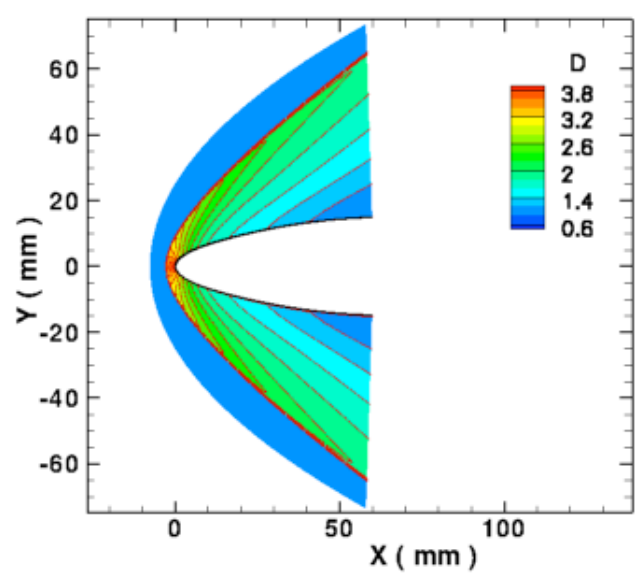

Figure 15. Contours of density for flow over an infinite swept wing with a blunt leading edge at $M=3.0$.
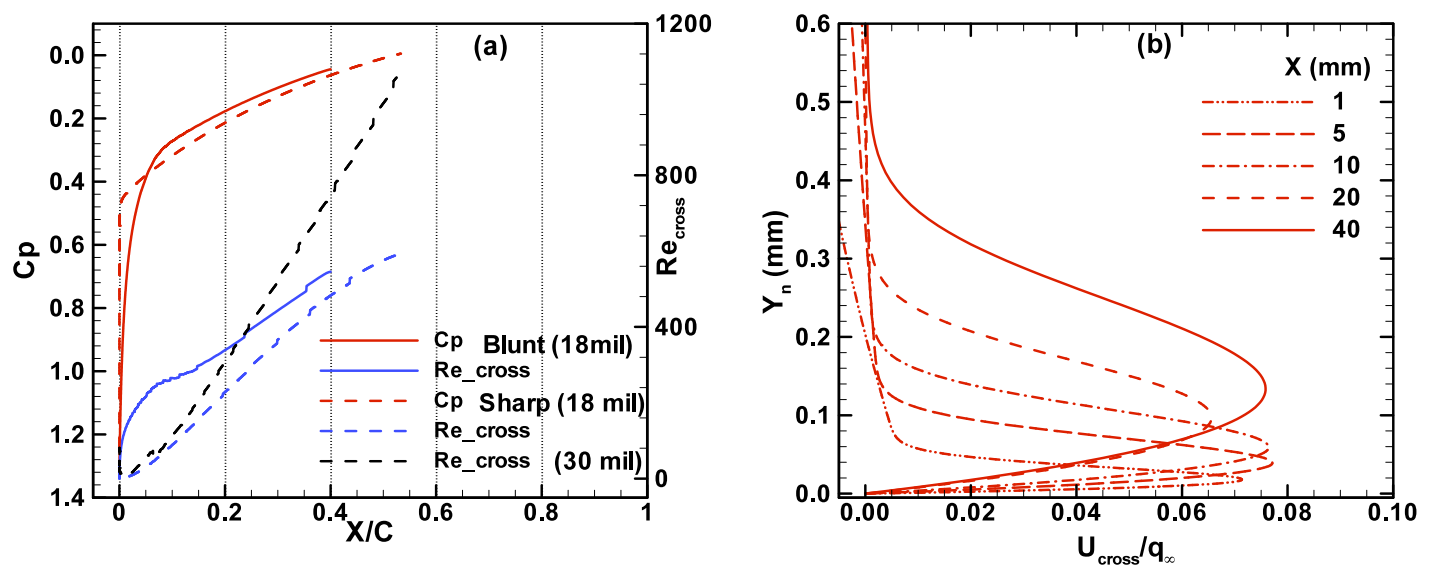

Figure 16. Computed (a) pressure distribution and the crossflow Reynolds number along the wing and (b) the crossflow velocity profiles at different stations for the blunt wing. 


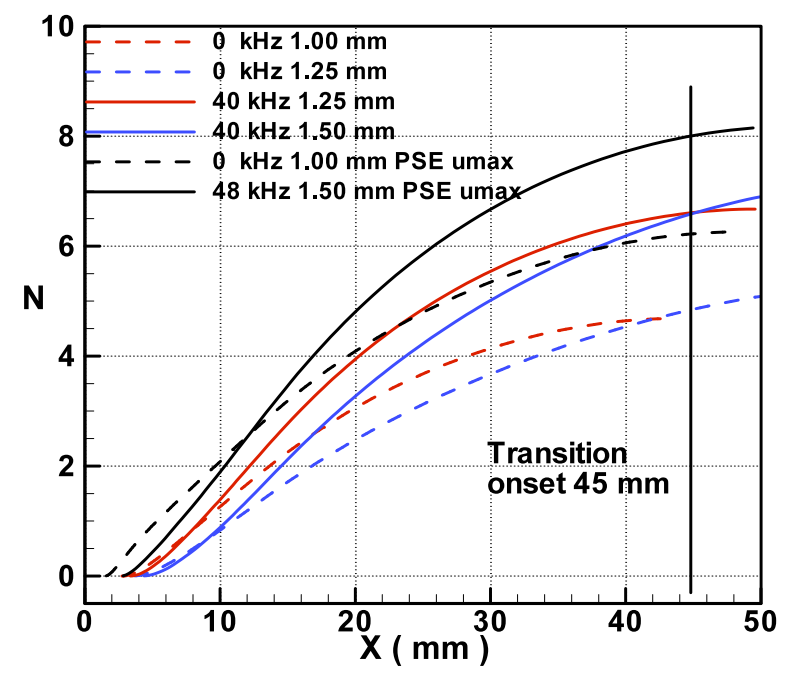

Figure 17. N-factors computed from local stability method for the stationary and traveling disturbances for the blunt wing.

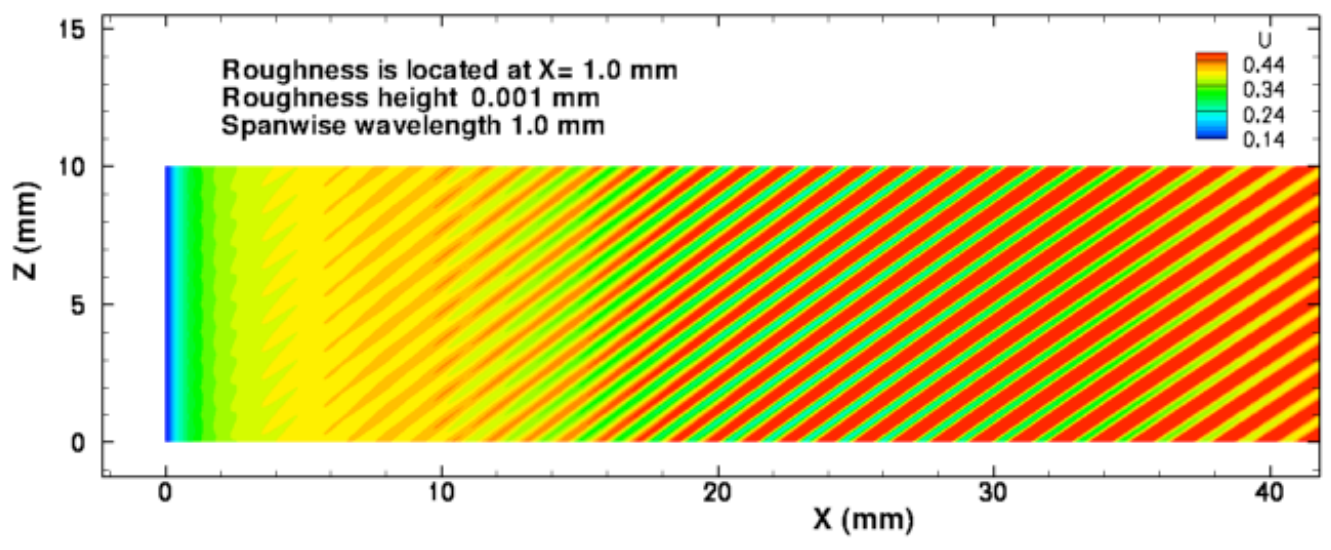

Figure 18. Contours of the $u$ velocity in the plan view $(x, z)$ plane for the blunt wing. 

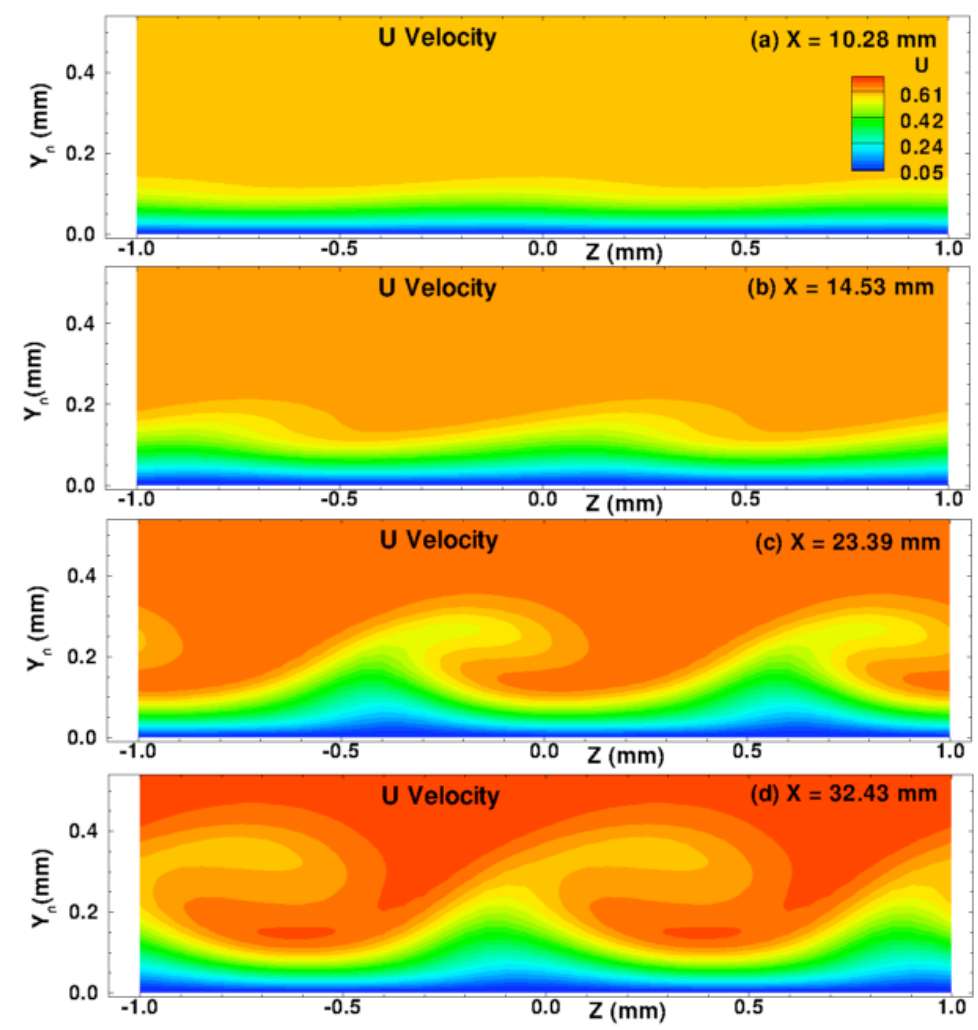

Figure 19. Contours of the $u$ velocity in the cross-sectional planes $(y, z)$ at different stations for the blunt wing.

(a)

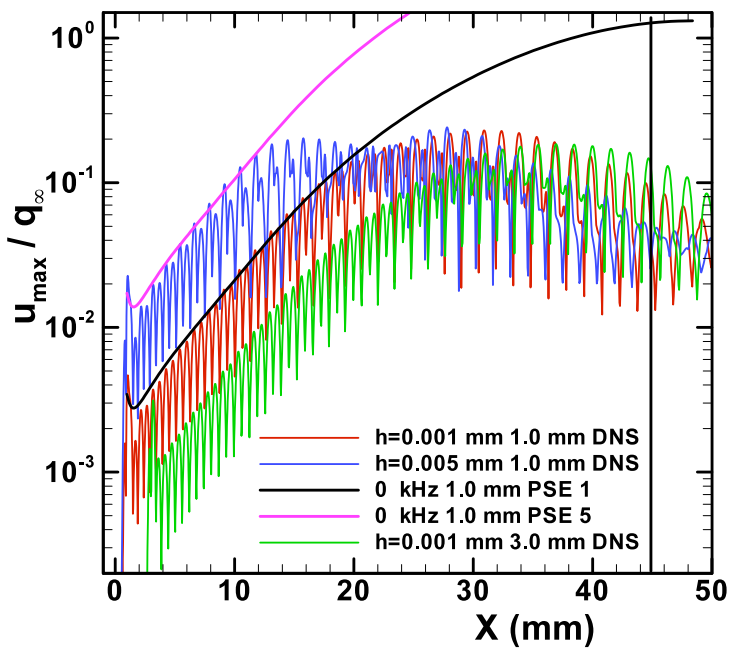

(b)

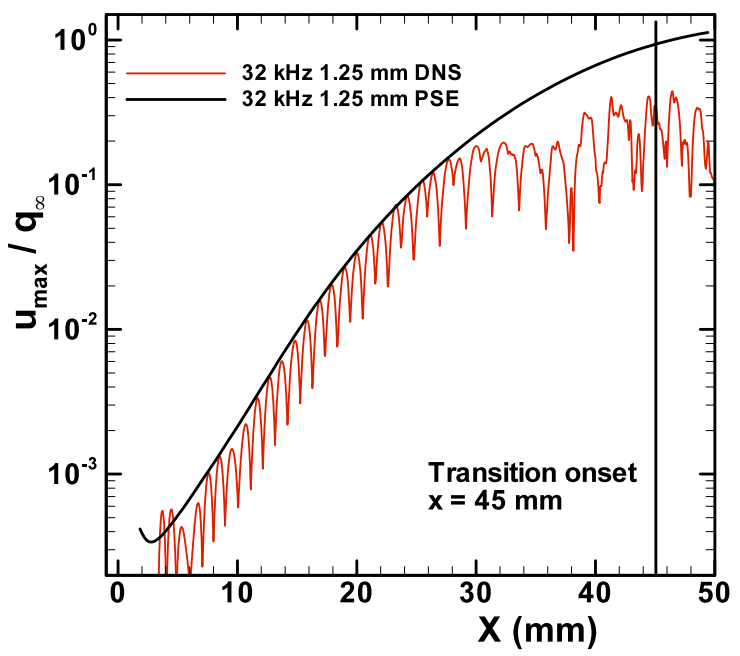

Figure 20. Perturbations of the maximum $u$-velocity component and PSE results along the blunt wing for perturbations (a) generated by the roughness and (b) generated by the blowing and suction. 